\title{
COPIM•
}

\section{New Thoth Releases and WP5 Updates}

Vincent W.J. van Gerven Oei, Rupert Gatti, Javier Arias, Timothy Elfenbein

Published on: Nov 04, 2021

DOI: $10.21428 / 785 a 6451 . c f a b 5944$

License: Creative Commons Attribution 4.0 International License (CC-BY 4.0) 


\section{Outreach/Community Building}

\section{Workshops and Listening Sessions with Scholar-led and University Presses}

On March 25, WP5 held a workshop providing a deep-dive into Thoth from a publisher's perspective. This was also an opportunity for the team to test drive the platform for a specific audience of stakeholders and gather suggestions for further improvement. As a result of the workshop, four additional publishers have started incorporating Thoth in their workflow: Mattering Press, meson press, mediastudies.press, and African Minds.

In the fall, members of the work package also held a number of one-on-one sessions with university presses and affiliated service providers in the North America and Europe, including the Central European University Press, the University of Michigan $\underline{\text { Press, }}$ and Longleaf Services, which is heading the Sustainable History Monograph Pilot (SHMP) with 22 university presses. The goal of the sessions was to better understand these presses' metadata packaging and dissemination workflows for their open-access titles. We learned about the use of title management and metadata packaging systems, significant gaps in the metadata dissemination infrastructure for open-access books, and the work-arounds press employees have developed.

\section{Outreach to Other Platforms}

Over the last few months, WP5 has already opened discussions with other platforms on their metadata requirements and possible future ways of metadata ingest. For Project MUSE, JSTOR, OAPEN/DOAB, and EBSCO, this has already led to concrete metadata formats that are available. Conversations with Google Books/Scholar and Memory of the World about possible ways of exposing Thoth metadata and/or ingesting OA books are currently ongoing.

\section{Updates in Thoth}

\section{User Manual}

The new Thoth User Manual is available via the Github repository wiki. This user manual explains all the core functions of Thoth and will continuously be updated with new information and best practices as the platform evolves. 


\section{Export API}

Thoth is supporting an ever-growing selection of metadata output formats. Our new Export API allows any user to export metadata of individual publishers or publications in ONIX 3.0 (Project MUSE, OAPEN, JSTOR); ONIX 2.1 (EBSCO Host); CSV; and KBART (OCLC).

\section{Upcoming in Thoth Version 0.5}

\section{Location Support}

In previous versions, Thoth stored location data (such as URLs and landing pages) in the Publication table. These location data will now be separated out into a separate table, allowing publishers to clearly organize the different Locations (type, landing page URL, and fulltext URL) at which individual Publications (paperback, hardback, $\mathrm{XML}, \mathrm{PDF}$, etc.) live, and which of those Locations holds the canonical version (or the version of record).

\section{ROR Support}

ROR (Research Organization Registry) is currently the largest open database for institutional identifies. And with the recent absorption of GRID, ROR is increasingly becoming the gold standard for institutional identifiers in metadata records. With v. 0.5, Thoth will add ROR support for Institutions (formerly the Funder table), which can be attached both to Works (as funder) or to Contributors (as institutional affiliation).

Update to Thema 1.4

In v0.5, Thoth will update from Thema 1.3 to Thema 1.4 subject classification scheme. Thema is currently the only open and most detailed subject classification scheme.

\section{Upcoming in Thoth Version 0.6}

\section{Chapter Support}

In v0.6, Thoth will implement many-to-many relations between the Work Types Monograph/Edited Book and Chapter. This will allow publishers to register individual chapters as part of a mongraph or edited book, and Thoth to export chapter metadata

\section{Thoth Python Client Version 0.6.0 Released}

We have published v0.6.0 of Thoth's python client, expanding the original GraphQL client, adding a client to the new export REST API, as well as a plugin for the Django 
framework and a CLI to all clients. The python client uses dynamic module loading to allow for incremental future updates as the data structure evolves. Developers may use this library to easily consume data from Thoth using the python programming language.

This update has been possible thanks to our colleague Martin Paul Eve, who is using this client to create the OBC platform, providing insight of Thoth's data. 